\title{
TOWARDS LOW CARBON HOMES - MEASURED PERFORMANCE OF FOUR PASSIVHAUS PROJECTS IN SCOTLAND
}

\author{
Tim Sharpe ${ }^{1}$ and Chris Morgan ${ }^{1}$ \\ ${ }^{1}$ Mackintosh Environmental Architecture Research Unit (MEARU), Glasgow School of Art, 167 Renfrew Street, Glasgow
} G3 $6 R Q$,

\begin{abstract}
Summary
This paper will describe the results of a 2-year monitoring programme of 4 Passivhaus dwellings in Scotland. The dwellings, part of a group of 8 houses, are built in a rural location in the South of Scotland to Passivhaus standards for private rent. Construction uses an offsite timber panel system. The dwellings rely on solar thermal hot water heating, backed up by a small biomass stove, which both feed a hot water cylinder. Ventilation and heating is via a Mechanical Ventilation Heat Recovery (MVHR) system, with a post heater from the water store. In theory therefore these buildings are zero carbon in terms of space and water heating. The dwellings have been monitored for a two-year period, gathering detailed data on internal environmental conditions, and energy use, including sub-metered electrical use, along with qualitative data from interviews with the occupants and design team. The wood fuel sources have also been tested for energy content and carbon factors. Other fabric tests such as thermography, u-value testing and airtightness have been conducted. This paper will report on the results of these tests and monitoring and describe the performance of these buildings in practice. In general the performance is very good, but significant differences in occupant behaviour are noted that can affect this, and the importance of incidental gains from non-regulated energy use from electrical consumption, which may undermine the zero carbon targets and which can contribute to overheating, are discussed, as is the relative performance of the MVHR system.
\end{abstract}

Key Words: Passivhaus, Energy Efficiency, Overheating, Zero Carbon, Airtightness, Occupant Behaviour

\section{Introduction}

The Scottish Government has set a target of $80 \%$ emissions reductions (from 1990) by 2050 with an interim target of 42\% reduction by 2020 (Scottish Government, 2009). In 2010 the Scottish Government set out a Low Carbon Economic Strategy (Scottish Government, 2010) that includes an ambition for all new buildings in Scotland to be zero carbon by $2016 / 17$ if practicable.

The strategy notes that barriers to a low carbon built environment include; investment cost; with focus on initial capital costs rather than 'whole life' costs; owners of buildings often not benefitting from improvements; and a general inertia to new investment and change. However a further barrier that is emerging in those buildings that are being built to these standards differences between design expectations and buildings in use. There is clear evidence of performance gaps between design expectations and building operation (GCB, 2012; Gill et al, 2011; ZCB, 2014), not just in terms of energy performance, but also issues such as comfort, indoor air quality and satisfaction (Crump et al, 2009; Monahan and Gemmell, 2013).

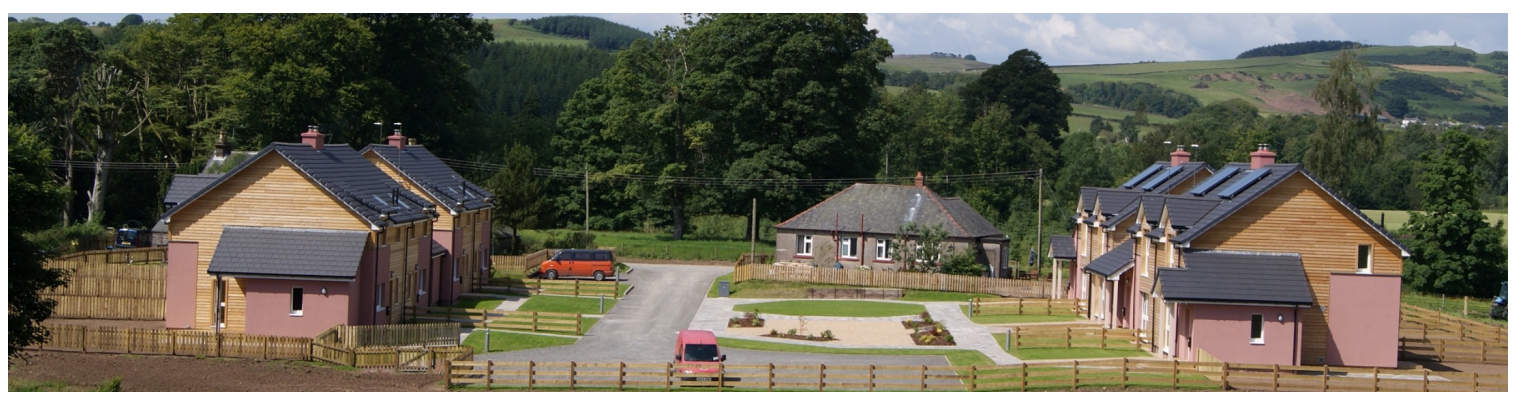

Fig. 1: Overview of the 8-house development from the East, showing the shared courtyard and rural setting. 
The Dormont Park Passivhaus development in the south of Scotland aimed to address these issues and has become an award winning rural development. It comprises 8 No. 2 and 3 bedroom houses built for long term affordable rent by the Dormont Estate. The development was completed in 2011 with the help of funding from the Scottish Government's Rural Homes for Rent grant scheme.

MEARU received funding through the UK Government Technology Strategy Board (TSB) Building Performance Evaluation (BPE) programme to study 4 No. of the buildings (2 No. 2-bed and 2 No. 3-bed) for a period of 2 years as a wider UK-wide programme of study into low energy new-build and refurbishment developments. The aim of the study was to assess how these buildings were performing in practice.

\section{Description}

The study comprised three areas of study, an investigation into the design and construction including a series of physical tests such as U-value, air-tightness, and thermography; a process of environmental and energy monitoring; and a series of occupant surveys, engagement and feedback.

\subsection{Design and Construction Investigation}

A construction audit was undertaken to identify design principles and construction details. Designed to Passivhaus standards from the outset, the construction method chosen was an offsite-built timber kit provided by a Glasgow-based firm. An $8.92 \mathrm{~m}^{2}$ flat plate solar thermal panel and a 'Woodfire F12 wood stove $(10.8 \mathrm{~kW}$ to water, $1.2 \mathrm{~kW}$ to room) provide heat for a central thermal store which delivers domestic hot water for direct use and also supplies space heating via a post-heater to the MVHR system. The thermal store also delivers heat to towel radiators in the bathroom as an overheat protection.
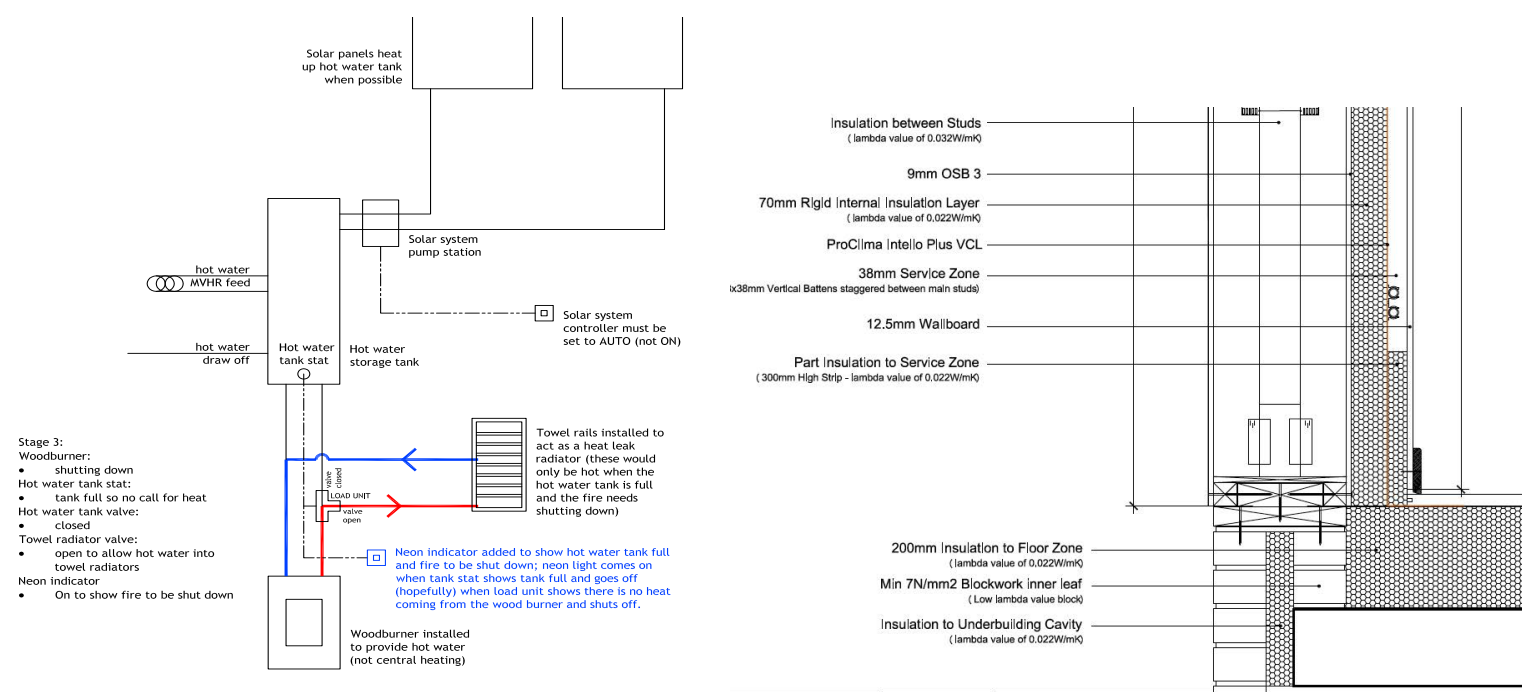

Fig. 2a: Schematic of the Services at Dormont, including wood stove, solar thermal panels, thermal store, heat dump towel rail and heating coil to MVHR post-heater: 2b Detail of the Wall / Floor junction used throughout the development

To complement the construction audit, interviews were held on site with the design team, contractor, client and separately, the occupants. This found that there was a good relationship between the members of the design team and the contractor adopted a strong design input post-tender stage and became the effective designer for details. This was the first Passivhaus development for the contractor and so there was a steep learning curve. The plumbing and electrical packages were contractor-design and this is where the majority of the problems were encountered.

\section{Test results}

A requirement of Passivhaus certification is an air change rate $(\mathrm{n} 50)$ of no more than $0.6 \mathrm{~m}^{2} / \mathrm{m}^{3} . \mathrm{h} @ 50 \mathrm{~Pa}$ and evidence from discussions with the contractor established that this was the hardest of all aspects to achieve on site. Air-tightness testing taken around 18 months after completion indicated a level of air leakage consistently four times worse (greater) than this level. This issue is discussed in more detail later.

A thermographic survey indicated a number of minor anomalies, but overall evidenced a very good level of 
thermal performance and consistency. On the other hand in-situ U-value tests gave results for the walls and roof respectively of $28.6 \%$ and $34.4 \%$ above the design values.

Tab. 1: Results of Insitu Testing of U Values at Cottage DA2.

\begin{tabular}{|c|c|c|c|c|c|}
\hline $\begin{array}{c}\text { Building Element } \\
\text { Tested (DA2) }\end{array}$ & Sample Period & $\begin{array}{c}\text { Sample } \\
\text { Duration }\end{array}$ & $\begin{array}{c}\text { Design U Value } \\
\text { (incl thermal } \\
\text { bridges) }\end{array}$ & $\begin{array}{c}\text { Measured U Value } \\
\text { (excl thermal } \\
\text { bridges) }\end{array}$ & $\begin{array}{c}\text { Deviation from } \\
\text { Prediction }\end{array}$ \\
\hline External (N) Wall & $\begin{array}{c}28.11 .13 @ 12.00- \\
13.12 .13 @ 11.50\end{array}$ & 359 hours & $0.1 \mathrm{~W} / \mathrm{m}^{2} \mathrm{~K}$ & $0.12 \mathrm{~W} / \mathrm{m}^{2} \mathrm{~K}$ & $28.6 \%$ \\
\hline $\begin{array}{c}\text { Roof (North } \\
\text { Facing) }\end{array}$ & $\begin{array}{c}28.11 .13 @ 12.00- \\
13.12 .13 @ 11.50\end{array}$ & 359 hours & $0.1 \mathrm{~W} / \mathrm{m}^{2} \mathrm{~K}$ & $0.12 \mathrm{~W} / \mathrm{m}^{2} \mathrm{~K}$ & $34.4 \%$ \\
\hline
\end{tabular}

MVHR systems were tested in each house, with imbalance (positive pressurisation) found in three of the four houses, with one example of an extract terminal installed behind ductwork such that it could not be tested (and could not have been correctly commissioned). Overall flow rates were acceptable for example DB1 has a flow rates of 40 1/s. However on a room-by-room bases rates are low. The average supply at normal setting for the living rooms over the four dwellings is $14.56 \mathrm{l} / \mathrm{s}$ which is marginally below the recommended rate of $(2 \times 8 \mathrm{l} / \mathrm{s}=16 \mathrm{l} / \mathrm{s})$ for two people and significantly so if there are more than two people in the room and this makes a case for a demand-led ventilation system.

A DomEARM (Domestic Energy Assessment and Reporting Methodology) audit was undertaken for each house indicating a generally low energy use, with the exception of one house where there was a high electrical use related to use of the immersion heater in preference to the wood stove and the impacts of this are discussed below.

\subsection{Environmental Monitoring}

A number of environmental characteristics were monitored remotely to minimise disruption to the occupants. There were temperature, relative humidity and $\mathrm{CO}_{2}$ levels in the living room, kitchen and main bedroom of each dwelling, along with contact sensors to monitor window opening. In addition weather information was gathered for the site overall.

\subsection{Occupant Surveys, Engagement and Feedback}

Basic occupant surveys were carried out to establish the key metrics for each dwelling. This was followed by semi-structured interviews with each occupant. The results showed that in general occupants were very pleased with their homes, with the only concerns relating to the overheating and comments relating to the time taken to understand the various services.

Occupants were also asked to fill in diaries, providing in-depth information on a number of subjects for the duration of a week. This was carried out across the various TSB-funded projects over the same week. The exercise allowed MEARU to corroborate potential anomalies in the monitored data with 'real life' information. For example, both occupants of this house spent 2 nights away during the week (Sun/Mon and Thur/Fri) and these absences are clearly represented in the $\mathrm{CO} 2$ readings for each bedroom.

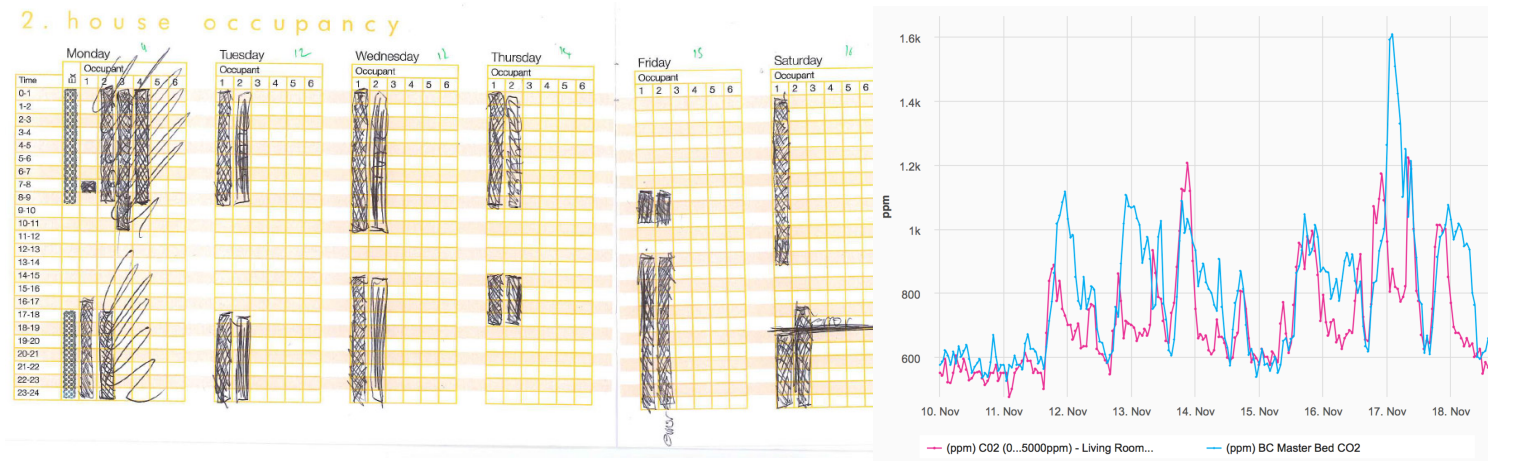

Fig. 3: Example of occupant diary: and monitored CO2 levels for the diary period 10/11/13 - 18/11/13 
Towards the end of the process, a BUS (Building Use Studies) questionnaire was undertaken. This is a detailed feedback form allowing direct comparison with other completed projects across the UK and indicated overall a high degree of satisfaction, not withstanding concerns about overheating and a variety of other minor issues.

\section{Main Findings}

\subsection{Energy Efficiency}

Energy use in the dwellings can be compared with 20 other low energy dwellings in Scotland being monitored as part of this TSB programme and this breakdown is shown in Figure 4. Overall the buildings are performing well against these buildings and most benchmarks. They offer strong evidence that the Passivhaus approach is a good way to create genuinely energy efficient buildings.

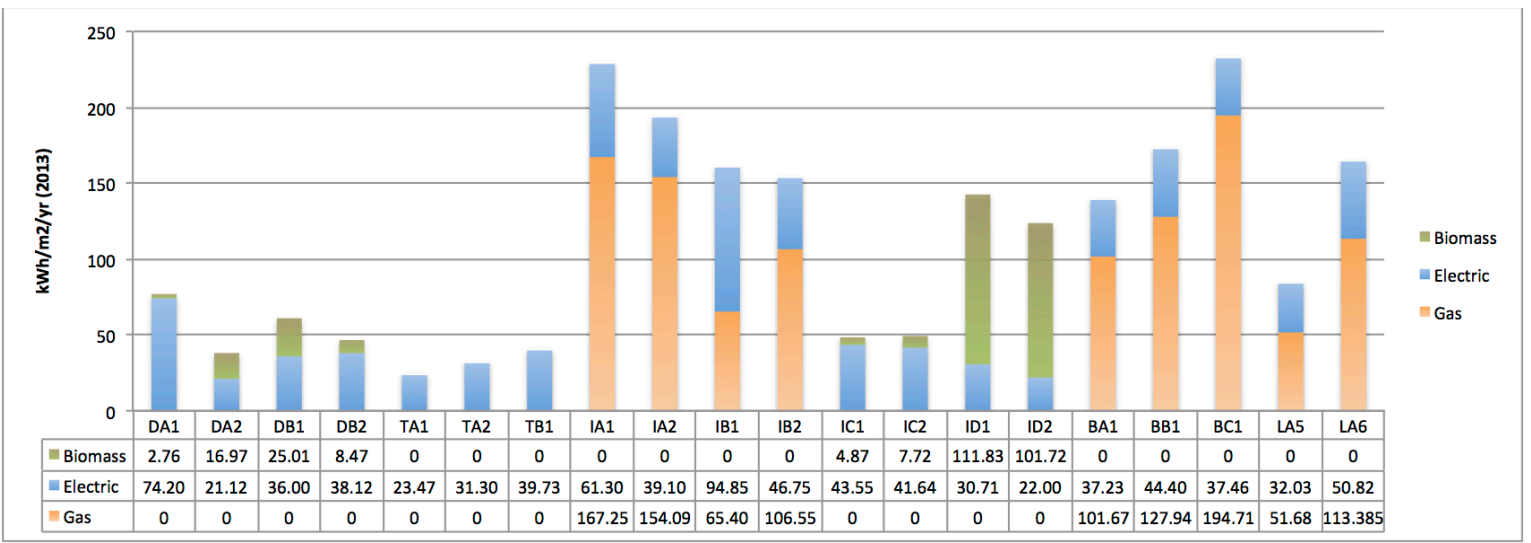

Fig. 4: Electricity, Gas and Biomass consumption for 2013 across 20 Scottish projects monitored by MEARU.

It is apparent that there are variations in overall consumption and reasons for this are discussed below. Variations in consumption will occur due to different house types, occupancy patterns and behaviour, as well as location. The figure below shows the same projects with primary energy totals calculated using PhPP conversion figures as noted.

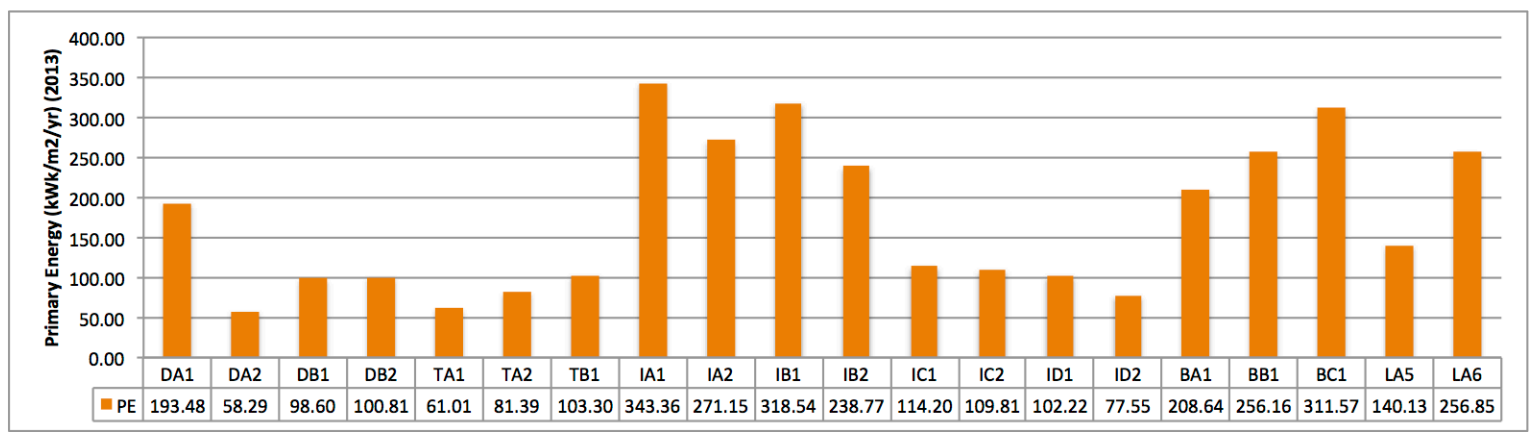

Fig. 5: Primary Energy consumption for same project as Fig 4. PE figures obtained through PhPP conversion: Electricity - 2.6 $\mathrm{kWh} / \mathrm{kWh}$, Gas - 1.1 kWh/kWh, Biomass - 0.2 kWh/kWh

With the primary energy mismatch between electricity, gas and biomass resolved, the differences are not as marked, but the Passivhaus principle of reducing space heating demand - regardless of what type of energy is used to provide warmth - can be seen to consistently lower energy use in relation to other low energy strategies. It also indicates the relative efficiency of flats, but does ignore the number of occupants.

The above figure also allows us to judge the properties against one of the important Passivhaus criteria which is a total (predicted) primary energy consumption, including a standardised allowance for unregulated energy of $120 \mathrm{~kW} / \mathrm{h} / \mathrm{yr}$. With the exception of DA1 all Passivhaus projects, and two other low energy dwellings, sit comfortably below this threshold. The relatively poor performance of DA1 is due to this tenants' preference for the electrical immersion heaters over the wood stove for almost all water heating, the causes of which are discussed below. 


\subsection{Zero Carbon and the importance of Unregulated Energy (Electricity)}

As an overall approach therefore, the Dormont properties can be seen to successfully reduce energy consumption, but the monitoring raised the effects of incidental gains on space heating. Total electricity consumption was monitored at the fiscal meter, while a series of clamp meters also measured each subcircuit within the house. This enabled a finer grain of understanding about energy consumption, and in particular, an assessment of the ratio between regulated and unregulated electricity use.

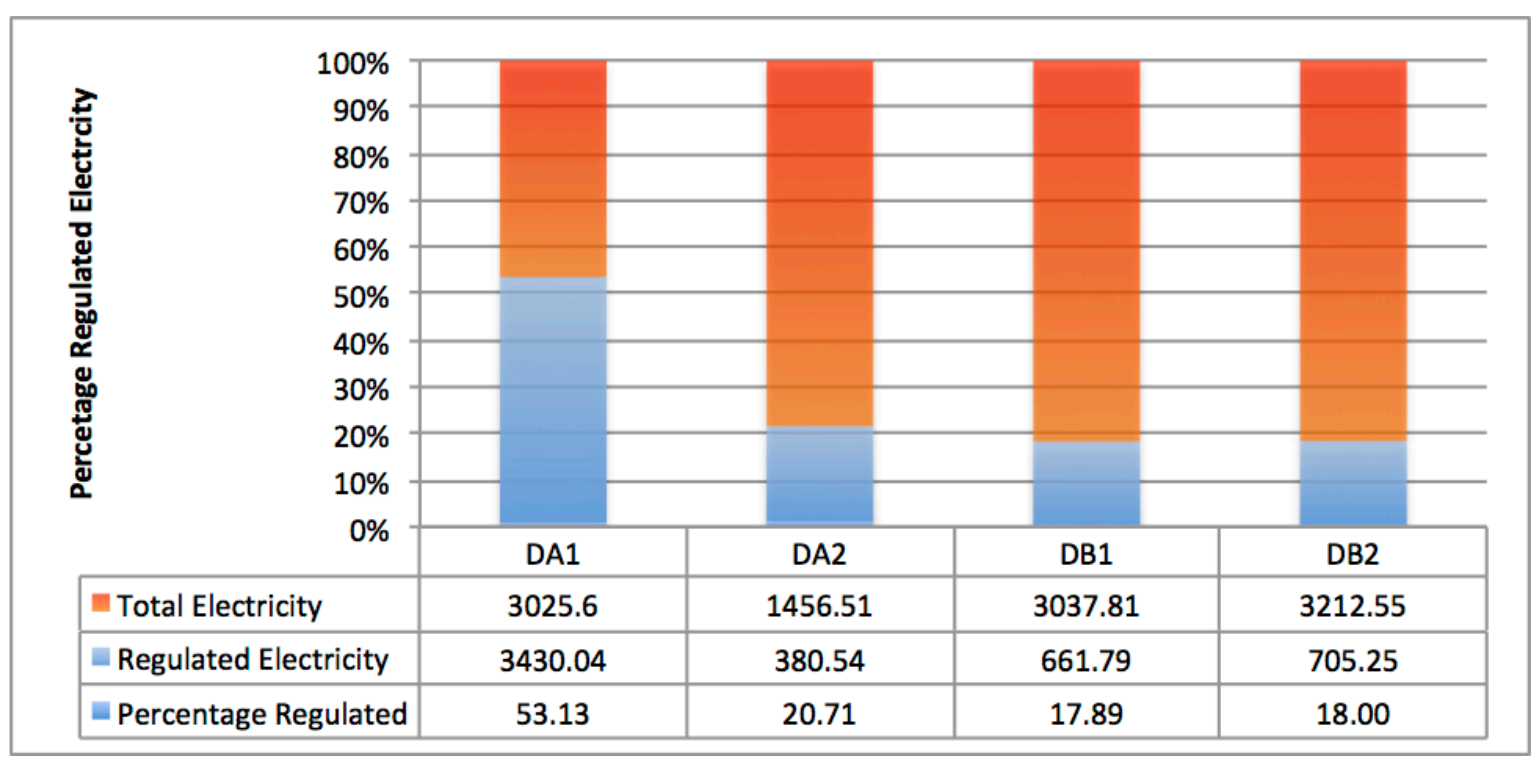

Fig. 6: Regulated (blue) electricity as a percentage of overall electricity consumption in the Dormont Houses, 2013.

In the context of low overall electricity consumption, the above graph shows the breakdown between the regulated energy (associated with lights, immersion heater, pumps and MVHR) as opposed to the unregulated electricity consumption associated with cooking, TVs, computers and charging appliances etc.

It is immediately striking that the regulated electricity consumption is a small percentage of the total, ranging from $53.13 \%$ to $17.89 \%$. Excluding DA1, the vast majority of electrical consumption at Dormont is unregulated. Frequently, this energy evades definitions of zero carbon performance because it is difficult to control. These findings however show the extent to which unregulated energy impacts on the total energy use and in particular the carbon output of buildings because mains electricity is relatively 'carbon dense.'

Although work is already being undertaken by manufacturers to reduce energy consumption of appliances, Figure 6 suggests that greater consideration should be given to how to manage this energy consumption. This may be a particular concern in affordable or social housing where occupants may be bringing older, relatively inefficient appliances, as replacement costs would be prohibitive This is reinforced when considering that a significant portion of space heating in highly insulated houses is likely to come from the use of unregulated devices such as televisions, computer and white goods etc. and this may be disguising a poor than expected carbon performance. In some instances this will beneficial and some use will correspond with occupancy (as appliances are un use when the house is occupied), but incidental heat delivery is always uncontrolled, and outwith heating the season, can contribute to overheating.

\subsection{Overheating}

It is clear from the results of the monitoring that the dwellings are providing a consistently warm environment with temperatures varying between $20^{\circ} \mathrm{C}$ and $25{ }^{\circ} \mathrm{C}$ for the majority of the time, only dropping when houses are unoccupied (Figure 7). In fact the principal and most widespread concern for occupants about the houses is that of overheating. The PhPP assessment established that there would be $0.2 \%$ overheating, ie $3 / 4$ of one day, or 18 hours in total across the whole year when the temperature in the house overall would rise above $25^{\circ} \mathrm{C}$. Figure 8 below shows a two week period during July 2013 , the temperatures in all four main bedrooms in each house rarely dip below $25^{\circ} \mathrm{C}$. In this instance external temperatures are not excessive, averaging about $18^{\circ} \mathrm{C}$. This represents a significant mismatch between PhPP assumption and reality. 


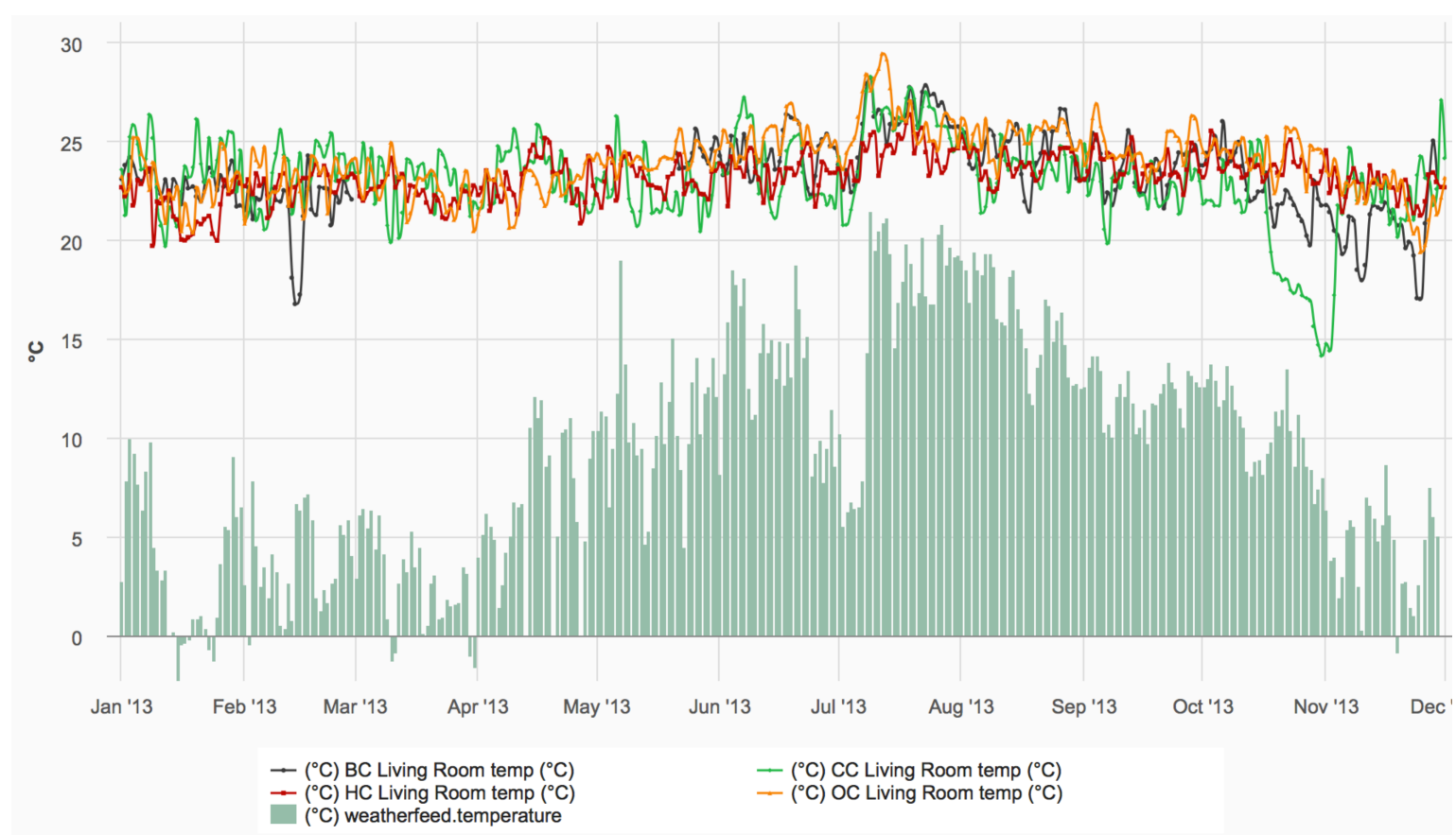

Fig. 7: Showing the temperature (in ${ }^{0} \mathrm{C}$ ) in all Living Rooms for 2013 with external temperatures plotted beneath.

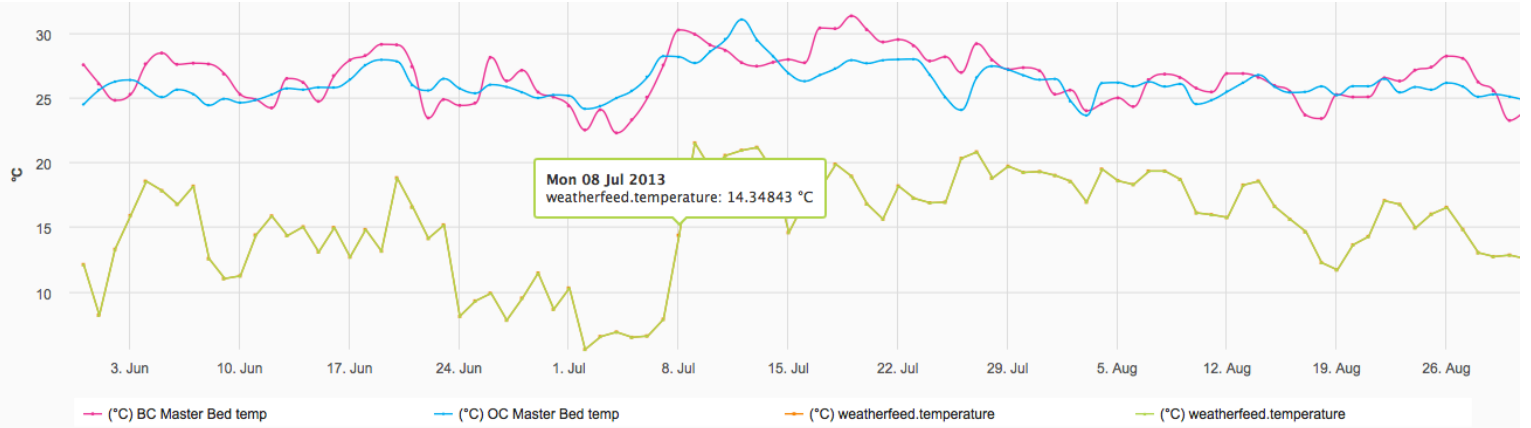

Fig. 8: Showing the temperature (in ${ }^{0} \mathrm{C}$ ) in bedrooms for the 2-week period July 7 th to 21 st. 2013.

There are likely to be a number of reasons for the overheating. The houses are well insulated and the fabric is relatively airtight and has little thermal mass, so the only effective way to remove heat is through ventilation. This will be the case in any season, but will be exacerbated in the summer months, especially to south facing apartments. The bedrooms are relatively small (especially in comparison to German space standards on which the Passivhaus standard is predicated) so heat cannot dissipate as readily, and upstairs rooms tend to gain heat through thermal stratification - average temperatures for the week were $1.9{ }^{\circ} \mathrm{C}$ warmer in the bedrooms. In addition, there is no external shading, no high level rooflight to exhaust warm air and in the case of the 2-bed houses, no summer bypass on the MVHR - all standard devices to reduce overheating. All of these are significant aspects and even taken in isolation could lead to overheating.

Window opening appears to have a minimal effect on overheating. "Any overheating can be managed easily by opening windows" reports one occupant in the BUS survey, but the monitoring has not shown much support for this. Examining a 5-day period and comparing temperatures with window opening, we see that in three of the houses, the bedroom windows are kept largely open. In one house - DB1 - the windows are closed for the latter three days. This has little effect on the overall internal temperatures in the bedroom, although in relation to the other three bedrooms, it goes from being consistently the lowest temperature, to being second or third, and the switch happens at exactly the time when the window is closed. This would suggest that opening the windows is helping to reduce the temperature, but the effect is marginal. Even with the windows open and a $12^{\circ} \mathrm{C}$ difference between internal and external air temperatures at the time of opening, the internal temperatures remain high. 


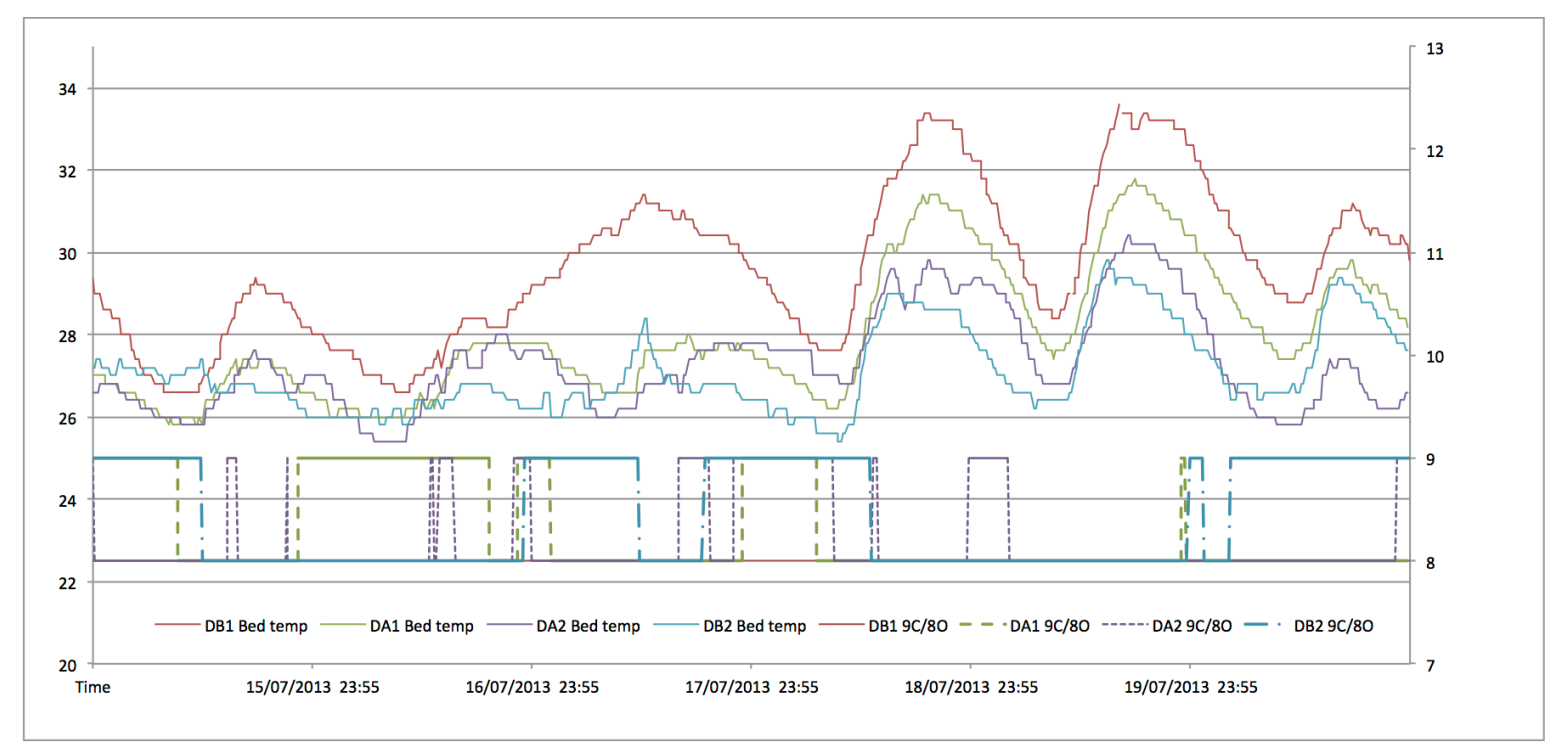

Fig. 9: Temperature and window opening in all South facing bedrooms for the 5 day period July 18th to $22^{\text {nd }}$.

A particular source of incidental gains in these houses is from uninsulated pipework. This was identified in the interviews with the design team as a deliberate decision on the understanding that all heat loss would be useful as it was inside the heated envelope (although pipework insulation is required in Passivhaus). Whilst this may have some benefit in winter it is an uncontrolled heat source. In summer this is a problematic gain, especially as domestic hot water use is relatively constant, but also because is exacerbated by the solar thermal system which generates more heat (then lost in distribution) in summer. The effects of this were identified in the thermographic survey. As a result those pipes easily accessed, in the cylinder cupboards, have been insulated by the estate, however hidden pipes remain un-insulated.

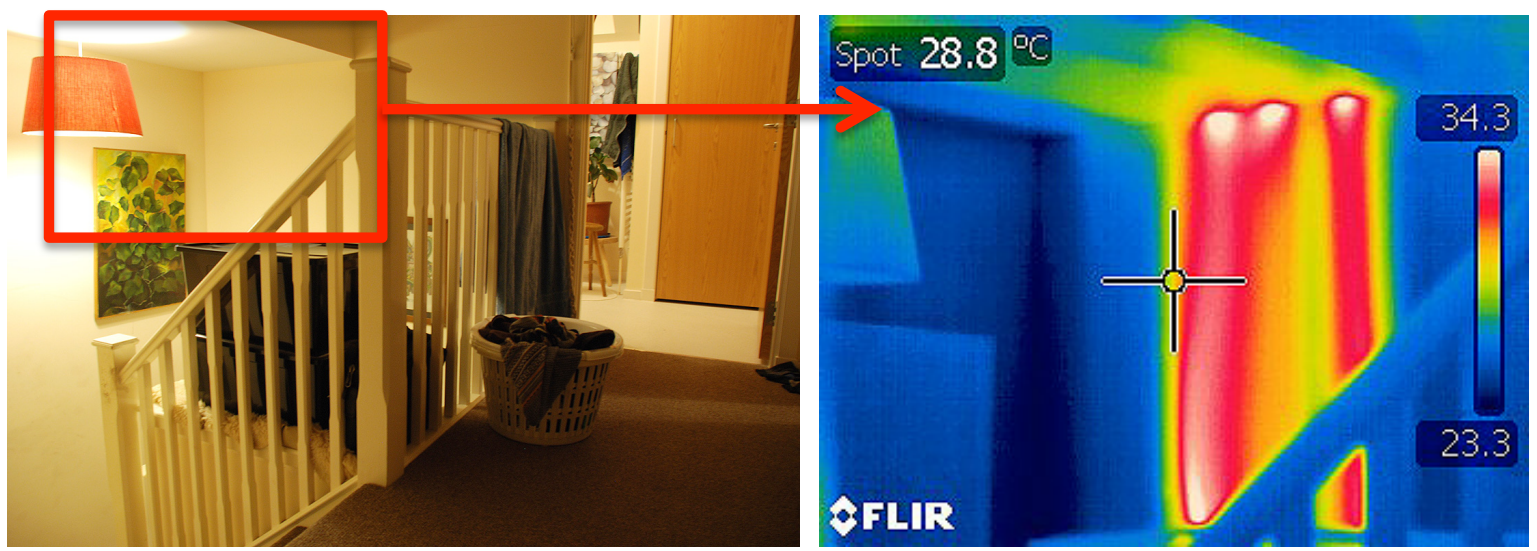

Fig. 10: Left: view of the stairwell and right: thermographic image of boxed area showing uninsulated hot water pipes running within.

This indicates is that a significant proportion of the heat demand is met through incidental gains. In relation to the zero-carbon agenda, the allocation of sources is very difficult to disentangle. A large proportion of these gains will be through electrical use (TVs, fridges, computers, lighting, pumps, fans, etc.), and whilst the principal source of hot water is low carbon (solar thermal and biomass) there are electrical immersion heaters which are used by occupants.

\subsection{Airtightness Irregularities}

A critical aspect of passivhaus certification is an air change rate (n50) of no more than 0.6.ac/h@50 Pa and pressure tests undertaken before completion gave satisfactory results (Table 2). Pressure tests were undertaken again at the same time as the installation of the monitoring equipment and were around $4 \mathrm{x}$ higher (worse) than previously, and $4 \mathrm{x}$ higher than allowable for passivhaus certification.

Without disruptive testing, it has not been possible to establish reasons for the dramatic, and consistent drop in performance. It is possible that that poor quality 'patching' was undertaken to get the right results in the 
short term. It was also noted that the testers had to return to the site on several occasions and this may have played a part in all involved seeking a short term solution. The first tests made at completion used 'copressurisation' to achieve the results, whereby adjacent properties are simultaneously pressurised (or depressurised). This tactic effectively removes anomalies caused by air leakage in party walls and is used in some cases, but is not deemed acceptable by the Air Tightness and Testing Measurement Authority (ATTMA), the governing testing authority. MEARU's first tests were undertaken without co-pressurisation so the second tests were undertaken using both to ascertain if this could be responsible for the discrepancies, but the was not the case. The later tests suggest that performance is not as poor, but remains well below the Passivhaus expectations.

Tab. 2: Results of 4no Pressurisation tests undertaken at Dormont

\begin{tabular}{|c|c|c|c|c|c|}
\hline Property & $\begin{array}{c}\text { Air change rate } \\
\text { required for } \\
\text { PHI (n50) }\end{array}$ & $\begin{array}{c}\text { Air change rate upon } \\
\text { completion (n50) (co- } \\
\text { pressurisation) }\end{array}$ & $\begin{array}{c}\text { Air change rate } \\
\text { by MEARU (1) } \\
\text { (n50) }\end{array}$ & $\begin{array}{c}\text { Air change rate by } \\
\text { MEARU (2) (n50) } \\
\text { (co-pressurisation) }\end{array}$ & $\begin{array}{c}\text { Air change rate } \\
\text { by MEARU (2) } \\
\text { (n50) }\end{array}$ \\
\hline DA1 & 0.6 & 0.581 & 2.410 & 1.78 & 1.88 \\
\hline DA2 & 0.6 & 0.515 & 2.125 & 1.58 & 1.64 \\
\hline DB1 & 0.6 & 0.501 & 2.495 & 1.59 & 1.66 \\
\hline DB2 & 0.6 & 0.530 & 2.210 & 1.38 & 1.55 \\
\hline
\end{tabular}

\subsection{Complexity}

A key characteristic of the project has been the relative complexity of the services and this has represented a problem for everyone involved in the project from the contractors, the client, the occupants, and for the monitoring project.

The complexity leads to a lack of overview and understanding, which can create unintended consequences. For example, the ground floor shower room towel rail was intended to be used as a 'heat dump' when there was excess heat in the system due to the wood stove having no thermostatic shut-off. However, this towel rail was initially fitted with a thermostatic valve preventing this from taking place. When the heat built up, the only escape was then for the hot water and steam to discharge via a low level pipe out into the garden. In DA1, the occupant was a young mother with a baby and she was naturally concerned when this occurred and, combined with concerns over safety with the fire and a lack of familiarity with wood stoves, decided not to use the wood stove. This meant that all heat and hot water was produced by the immersion heater leading to the significant electricity use discussed previously.

In trying to identify the location and specification of services it has been very difficult to trace information back 'upstream'. There are significant differences between the design schematics, the as-built drawings and what can be identified on-site, the latter made worse as many elements are built into the fabric of the dwelling (e.g. the pipework referred to earlier and also MVHR ductwork) and cannot be easily accessed for maintenance or repair. There was uncertainty about whether the MVHR systems did or did not have summer bypass (the 3-bed houses do, but not the 2-bed houses), and there was confusion about the purpose of some elements of the controls, such as the thermostats. This was compounded by installation errors, for example the hot water immersion switch was initially located in the loft, and left permanently on, and the thermostatic control of the MVHR post-heater was discovered not to have been connected properly so that it did not, in fact, adequately adjust the heat input into the house.

The issue is exacerbated by the unfamiliarity of many of the passivhaus measures for those on site, but it pertains especially to active renewable systems, particularly when these comprise a series of separate components, with different controls, installed by different people.

A key message emerging from the project is that these elements need to be considered, specified and settled at early stages. This allows information on the function and control to be carried through the construction phase and, most importantly, clearly communicated to the client and occupants, but latterly, those charged with maintenance and replacement. There was clearly a learning curve for all those involved in the project and this will be a challenge as such buildings and strategies become mainstream. Traditional practice and 
thinking - exemplified through the assumption that heat gains from pipework is beneficial due to the current high heat demand of existing houses - need to be changed.

It is perhaps a simple but worthwhile observation that while passivhaus and renewables installations are in their infancy (in Scotland) that it is important to exercise as much care with the initial design of the services as with the building fabric.

\subsection{Conclusions: So are they Passivhaus?}

On the basis that the PhPP sheets for the houses were assessed and approved, and that compliant airtightness results and MVHR commissioning sheets were submitted at completion, then it can said that the houses are indeed Passivhaus, regardless of what may be established subsequently.

However, on the basis that so soon after completion, it has been shown that the critical aspect of airtightness is not at the level required of a passivhaus, nor that the MVHR commissioning could feasibly have been undertaken properly undermines the validity of that certification.

Nevertheless the overall energy consumption is shown in Figure 11, which compares space heating energy use with the Passivhaus standard. These figures however are only indicative and cannot be taken as accurate. They are dervived from incorporating $10 \%$ of the total electrical consumption as an allowance of the contribution to space heating from such incidental gains, $10 \%$ of the biomass consumption (Manufacturer's stated percentage of direct room output compared to hot water provision) and the hot water flow results to the MVHR post-heater. However some two post-heater flow results are suspect, rendering the final figures equally uncertain.

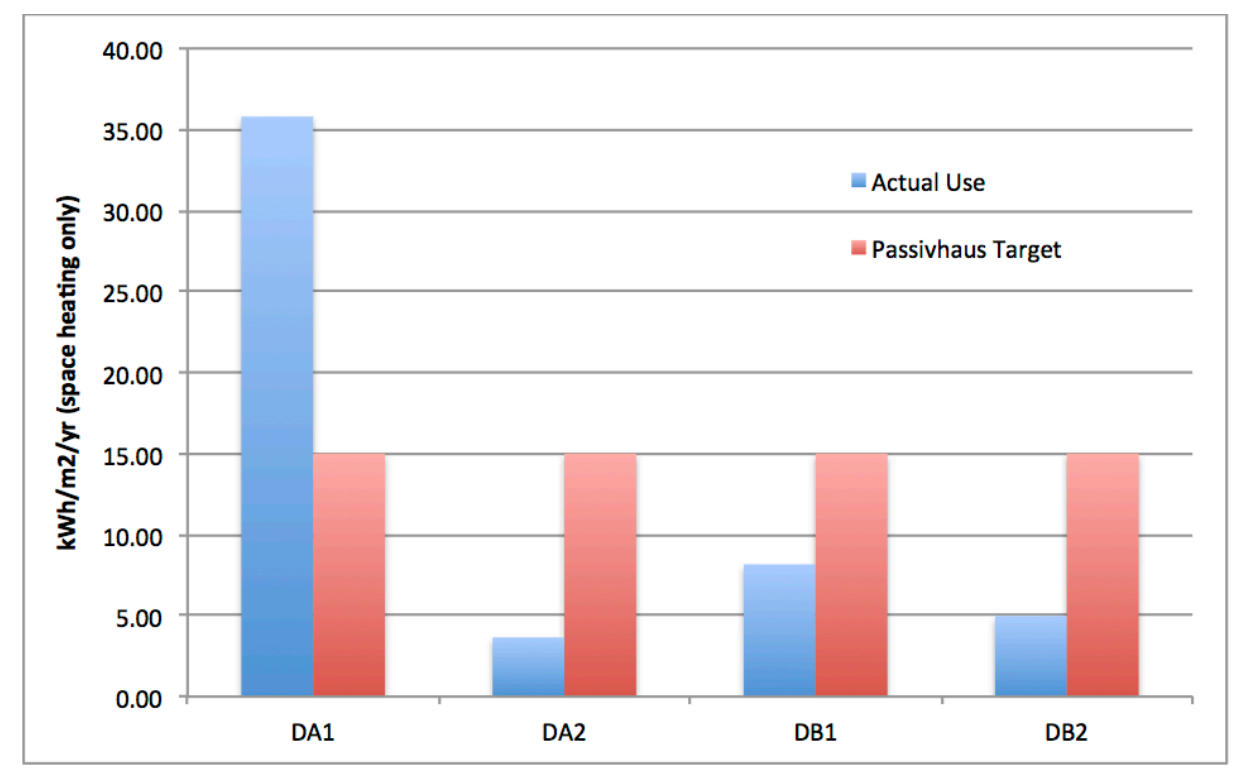

Fig. 11: Actual annual space heating energy consumption per square metre for Dormont Park in 2013 in blue against Passivhaus threshold of $15 \mathrm{kWh} / \mathrm{sq} \cdot \mathrm{m} / \mathrm{yr}$.

There are other problems with trying to establish a reliable space heating demand that can be directly compared with the Passivhaus prediction. The principal one is differentiating between space and water heating when considering the service arrangements at Dormont. Another is that it is impossible to clarify what level of heat input contributes to overheating, where the Passivhaus prediction is based on achieving a constant $20^{\circ} \mathrm{C}$. In addition, it is impossible to disentangle occupant behaviour from building performance, although this can be achieved to an extent by averaging out each result. In this case, the average of the four dwellings is $13.15 \mathrm{kWh} / \mathrm{m}^{2} / \mathrm{yr}$, so within the threshold. For these reasons, whilst the figure below gives an indication of space heating performance, a more reliable indication of whether the buildings achieve the passivhaus aspirations can be found in Figure 5, which measures primary energy consumption allowing for unregulated electrical use.

Finally to ask the question as to whether the houses are nonetheless operating 'at a level consistent with 
passivhaus certification' then the answer is certainly "Yes" and the dwellings are well within the limits of affordability for their occupants. Dormont Estate decided to opt for Passivhaus certification rather than other energy or sustainability benchmarks because they believed that that was the route to more robust performance and there is little doubt that their conviction has been vindicated.

\section{References}

Scottish Government, 2009. The Climate Change (Scotland) Act 2009

Scottish Government, 2010. A Low Carbon Economic Strategy for Scotland, Edinburgh. Available from Scottish Government website. http://www.scotland.gov.uk/Publications/2010/1 1/15085756/0 accessed May 2014.

Sullivan, L. 2007. A low carbon building standards strategy for Scotland. Published by the Scottish Building Standards Agency. http://www. sbsa.gov. uk/pdfs/Low_Carbon_Building_Standards_Strategy_For Scotla nd. pdf. [accessed May 2014]

Green Construction Board Buildings Working Group, 2012. The Performance Gap: Causes \& Solutions Available: http://www.greenconstructionboard.org/index.php/resources/performance-gap [accessed May 2014]

Gill, Z. M., Tierney,M.I., Pegg, I. M.; and Allan, N. 2011. Measured Energy and Water Performance of an Aspiring Low Energy/Carbon Affordable Housing Site in the UK. Energy and Buildings 2011, 43 (1): 117125

Zero Carbon Hub, 2014. Closing the Gap between Design and As-Built Performance - End of Term Report accessed at: www.zerocarbonhub.org [accessed May 2014]

Crump D., Dengel A., Swainson M., 2009. Indoor Air Quality in Highly Energy Efficient Homes - a Review. NHBC Foundation NF18, IHS BRE Press, London.

8 Monahan, S., Gemmell, A. 2013. How Occupants Behave and Interact with Their Homes. NHBC Foundation 2011 NF35, available online:

http://www.nhbcfoundation.org/Researchpublications/tabid/339/Default.aspx [accessed May 2014]. 